\title{
EFFECT OF WHITENING ON THE OPTICAL AND MECHANICAL PROPERTIES OF AGED RESIN COMPOSITES

\author{
Ingrid Fernandes Mathias-Santamaria ${ }^{1 \mathrm{a}}\left[\mathbb{C}\right.$, Ayla Macyelle de Oliveira Correia ${ }^{\text {b }}$, Débora Cristina Barbosa Dantas'c, \\ Márcia Carneiro Valera ${ }^{\text {td }}$, Renata Marques de Melo ${ }^{2 e}$, Eduardo Bresciani ${ }^{11^{*}}$ (iD
}

'Department of Restorative Dentistry, Institute of Science and Technology, São Paulo State University, São José dos Campos, Brazil

${ }^{2}$ Department of Dental Materials and Prosthodontics, Institute of Science and Technology, São Paulo State University, São José dos Campos, Brazil

\author{
a,b,c, DDS, MSc, PhD Student \\ ${ }^{d} D D S$, MSC, PhD, Full Professor of Endodontics \\ eDDS, MSc, PhD, Researcher Professor \\ 'DDS, MSc, PhD, Associate Professor of Operative Dentistry
}

\begin{abstract}
Objectives: To evaluate the effect of bleaching on colour, gloss, translucency, and microhardness of two types of resin composites (Charisma Classic and Filtek Z350 XT), previously aged.
\end{abstract}

Materials and methods: Forty specimens of each material were artificially aged for 300 hours (UV-accelerated aging). Specimens were then treated with 35\% hydrogen peroxide (Whiteness HP) in four 15-minutes sessions, totaling one hour of bleaching. Colour coordinates CIE L*a*b* and parameters of translucency (PT) were measured using a spectrophotometer (CM2600d - Konica Minolta), surface gloss readings were performed with a glossmeter (Novo-Curve - Rhopoint TM), and microhardness was assessed using a hardness device (FM-700, Future-Tech). Measurements have been performed after artificial aging as well as after the first and last bleaching protocol. Data were analyzed by two-way ANOVA and two-way repeated measures ANOVA, followed by Tukey's test (5\%).

Results: The bleaching procedures of aged resin composites decreased the gloss and increased the translucency, but did not alter colour and microhardness.

Conclusion: Bleaching procedures should be used carefully when resin composite restorations are present.

Keywords: colour, hardness, gloss, bleaching agents, composite resins.

\author{
OPEN ACCESS This is an Open Access \\ Oarticle under the CC BY-NC 4.0 license. \\ Eeer-Reviewed Article \\ Citation: Mathias-Santamaria IF, de Oliveira Correia \\ AM, Barbosa Dantas DC, Carneiro Valera M, de Melo \\ RM, Bresciani E. Effect of whitening on the optical and \\ mechanical properties of aged resin composites. Stoma \\ Edu J. 2018:5(3):161-167 \\ Academic Editor: Nicoleta llie, Dipl-Eng, PhD, \\ Professor, Ludwig-Maximilians-Universität München, \\ München, Germany \\ Received: August 21, 2018 \\ Revised: September 05, 2018 \\ Accepted: September 11, 2018 \\ Published: September 17, 2018 \\ *Corresponding author: Assoc. Professor Eduardo \\ Bresciani, DDS, MSc, PhD, Department of Restorative \\ Dentistry, Institute of Science and Technology, \\ São Paulo State University, Av. Eng. Francisco Jose \\ Sao Paulo State University, Av. Eng. Francisco José \\ Longo, 777 , Sa o Jose dos Campos, SP, Brazil, ZIPCCOEE \\ Fax: +55 1239479048, e-mail: \\ eduardob@ict.unesp.br \\ Copyright: $\odot 2018$ the Editorial Council for the \\ Stomatology Edu Journal.
}

\section{Introduction}

Dental bleaching is a conservative alternative with high success rates for treating discoloured teeth [1]. Tooth bleaching is a chemical process, which is performed with peroxide, chlorine, or chloride based-products. Among the products, hydrogen peroxide is the most commonly used agent. The bleaching process relies on the decomposition of peroxide into free radicals, while unstable molecules, such as tooth pigments, uptake electrons for stabilization [2]. Basically, the formed free radicals break up the double-bonds of the pigment's complex chains, resulting in a lighter pigment. This process represents the oxidative reaction of pigments within tooth structures.

Studies have reported that bleaching agents might affect the properties of resin composites; this influence is dependent on the bleaching agent and its concentration, as well as on the type of restorative material tested [3-6]. Microhybrid resin composites seem to undergo greater colour changes than nanohybrid ones; and the concentration of the bleaching agent seems to be less important than the time exposed to such products, although there are reports stating the higher the concentration the greater the bleaching efficacy on a determined period of time [5]. Regarding surface gloss assessment, previous studies [7-9] concluded that bleaching agents are able to reduce significantly the gloss of resin composites, thus changing the aesthetic property of restorations. Bleaching procedure alters the colour of resin composite materials [6], but not the translucency. The literature is still controversial regarding the microhardness of resin composites after bleaching procedures. It has been reported that bleaching treatment with $10 \%$ carbamide peroxide decreased the surface microhardness of resin composites by $15 \%$ of its baseline value [10]. However, there are available studies on reduced $[9,11,12]$ or even increased [13] microhardness, when testing nanofilled resin composites.

The influence of bleaching on resin composites is explained by a surface degradation and the presence of microcracks on the surface, which is aggravated over time [14]. Despite those studies, considering colour, gloss, translucency and surface hardness, the literature is not conclusive about the influence of bleaching treatment on the surface of different resin composites $[3,5]$.

To simulate clinical condition several in-vitro studies uses artificial aging of resin composites. For those, artificial aging by UV light and moisture or water immersion protocols [15] have been proposed [16,17] By employing artificial aging, the mechanical properties 
of resin composites are negatively influenced over time due to filler degradation [18], or matrix plasticization [19]. The influence of isolated artificial aging or bleaching procedures over resin composites is well documented. The association of both parameters is usually tested using a bleaching procedure followed by artificially accelerated aging. Studies with that purpose have shown that colour and roughness of resin composites were significantly changed depending on resin type $[16,17]$.

To the best of our knowledge, there are limited studies identifying potential problems that bleaching may result on the properties of previously aged resin composites, especially regarding the optical properties. Bleaching employed over aged resin composite restorations is a usual scenario faced in clinical practice. Therefore, the aim of this study is to evaluate the optical (colour, gloss and translucency) and mechanical (microhardness) properties of two types of resin composite, previously aged and whitened. The Null hypothesis is that none of the variables (colour, gloss, translucency microhardness) is affected by the bleaching procedure considering the independent variables tested (type of resin composite and time of bleaching).

\section{Materials and methods \\ 2.1. Sample preparation}

The characteristics of the tested resin composites are shown in Table 1.

A total of 20 samples of each material were prepared for assessing colour, translucency, and gloss. Resin composite was placed in a single increment into a standardized circular matrix, $6 \mathrm{~mm}$ in diameter and $1 \mathrm{~mm}$ thick for specimen preparation. For the microhardness assessment, a total of 20 samples of each material were prepared, $3 \mathrm{~mm}$ in diameter and $1 \mathrm{~mm}$ thick. The molds and materials were covered with Mylar strips on the top and bottom and placed between two cover glasses. Finger pressure was then applied to extrude the excess of material and to promote an even and smooth surface. Specimens were light-cured (Radii Cal curing light, SDI, Victoria, Australia; $440-480 \mathrm{~nm}, 1200 \mathrm{~mW} / \mathrm{cm}^{2}$ ) according to the manufacturer's instructions (20 seconds for both materials). The irradiance of the light-curing unit was assessed with a radiometer (Ecel, Ribeirão Preto, Brazil) prior to the fabrication of specimens. The samples were stored in ultrapure water for 24 hours at $37^{\circ} \mathrm{C}$, to allow post-curing.

The specimens were positioned inside a metal holder, and the surface that would be treated with the bleaching therapy was polished with sequential (P1200, P2400, and P4000 grit) aluminum oxide abrasive papers (FEPA-P, Struers, Ballerup, Denmark) in a polishing device (DP-10, Panambra Industrial e Técnica SA, São Paulo, SP, Brazil) for 30 seconds on each paper (Fig. 1).

\subsection{Accelerated artificial aging}

After polishing, the samples were artificially aged in a weathering machine (SUNTEST CPS+ - Atlas Material Testing Technology, Mount Prospect, Illinois, USA), following ISO 7491 standard. One hundred aging cycles were performed (300 hours in total). Each cycle was composed of two hours at $55 \pm 5^{\circ} \mathrm{C}$ and
Iable 1. Characteristics of resin composites tested in the present study.

\begin{tabular}{|c|c|c|c|c|c|}
\hline Composite & Shade & Type & Composition & $\begin{array}{l}\text { Manu- } \\
\text { facturer }\end{array}$ & LOT \\
\hline $\begin{array}{l}\text { Charisma } \\
\text { Classic }\end{array}$ & $\mathrm{A} 2$ & $\begin{array}{l}\text { Micro- } \\
\text { hybrid }\end{array}$ & $\begin{array}{l}\text { Bis-GMA, } \\
\text { TEGDMA, barium } \\
\text { aluminium fluoride } \\
\text { glass ( } 0.02-2 \\
\text { microns) and } \\
\text { highly dispersive } \\
\text { Siliciumdioxyde } \\
\text { ( } 0.02-0.07 \\
\text { microns), with } 78 \% \\
\text { filler content by } \\
\text { weight }\end{array}$ & $\begin{array}{l}\text { Heraeus } \\
\text { Kulzer, } \\
\text { Hanau, } \\
\text { Germany }\end{array}$ & 010027A \\
\hline $\begin{array}{l}\text { Filtek } \\
\text { Z350XT }\end{array}$ & $\mathrm{A} 2$ & $\begin{array}{l}\text { Nano- } \\
\text { hybrid }\end{array}$ & $\begin{array}{l}\text { Bis-GMA, Bis- } \\
\text { EMA, UDMA, } \\
\text { and TEGDMA; } \\
\text { 20-nm nanosilica, } \\
\text { and 5- to } 20 \text {-nm } \\
\text { zirconia nano } \\
\text { agglomerates, with } \\
78.5 \% \text { filler content } \\
\text { by weight }\end{array}$ & $\begin{array}{l}\text { 3MESPE, } \\
\text { St Paul, } \\
\text { MN, USA }\end{array}$ & 96374 \\
\hline
\end{tabular}

Bis-GMA: bisphenol A-glycidyl ether dimethacrylate; UDMA: urethane dimethacrylate; TEGDMA: triethylene glycol dimethacrylate; Bis-EMA: ethoxylated bisphenol A-dimethacrylate.
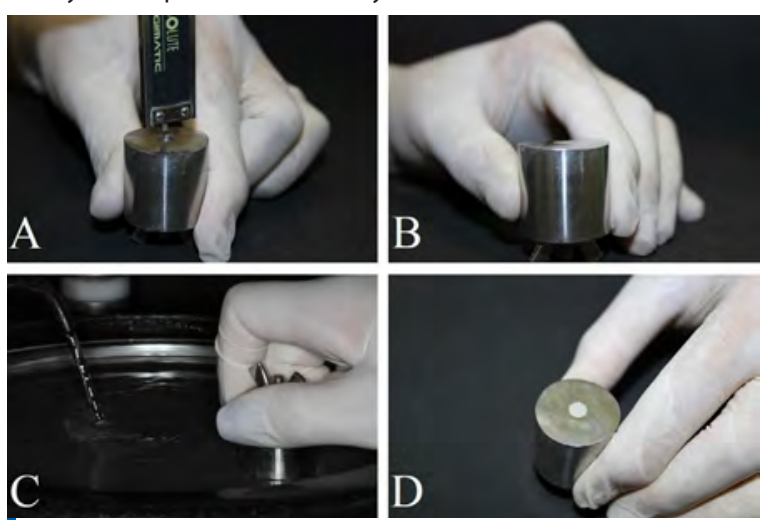

Figure 1. Sequence of the polishing step. A. Thickness standardization; B. Specimen in position inside the metal holder; C. Polishing; D. Final aspect.

I Table 2. Composition of the artificial saliva according to Göhring et al., 2004.

\begin{tabular}{cc}
\hline Component & $\mathrm{mmol} / \mathrm{l}$ \\
\hline Potassium & 22.1 \\
Sodium & 16.1 \\
Hydrogen phosphate & 14.5 \\
Boric acid & 2.6 \\
Calcium & 0.8 \\
Thiocyanate & 0.7 \\
Magnesium & 0.4 \\
pH & 0.2 \\
\hline
\end{tabular}

irradiation at $765 \mathrm{~W} / \mathrm{m}^{2}$, followed by one hour at 37 $\pm 5^{\circ} \mathrm{C}$ and no light irradiation, totaling 3 hours each cycle. That protocol simulates exposure of $160 \mathrm{klux}$, corresponding to intense natural light, equivalent to one year of clinical use [20]. During the artificial aging, samples were immersed in artificial saliva at $37 \pm 1^{\circ} \mathrm{C}$ (Table 2) [21]. 


\subsection{Colour assessment}

The colour coordinates of each specimen were assessed, under standardized ambient conditions, according to the CIE L*a*b* system, using a reflectance spectrophotometer (CM2600d, Konica Minolta, Osaka, Japan). The device was adjusted to D65 standard illuminant with $100 \%$ UV and specular component included ( $\mathrm{SCl}$ ). The observer angle was set at $2^{\circ}$ and the device was adjusted to a small area view (SAV). The colour of each sample was measured three times, obtaining an average of $\mathrm{L}^{*} \mathrm{a}^{*} \mathrm{~b}^{*}$ chromatic coordinates, as established by the Commission Internationale de I'Eclariage (CIE), which locates the colour of an object in a three-dimensional colour space. The $L^{*}$ axis represents the degree of lightness within a sample and ranges from 0 (black) to 100 (white). The $a^{*}$ axis represents the degree of the green/red colour within the sample, while the $b^{*}$ axis represents the degree of the blue/yellow colour within the sample. The colour was measured over white ( $L^{*}$ : 84.95; $a^{*}$ : $\left.-0.38 ; b^{*}: 2.93\right)$ and black ( $L^{*}$ : 2.58; $\left.a^{*}:-0.15 ; b^{*}:-0.24\right)$ standard backgrounds (Ceram, Staffordshire, UK) [22]. Optical contact between the specimen and the backgrounds was improved by using an interfacing layer of a polyethylene glycol 400 solution (LabSynth, Diadema, São Paulo, Brazil) [22]. From the colour measurements after the artificial aging and after the first or last week of bleaching, the values of the changes of $L^{*}(\Delta L), a^{*}(\Delta a)$, and $b^{*}(\Delta b)$ were calculated. Next, the total change in colour or the variation in perception of colour of each specimen was calculated, designated by the abbreviation $\Delta \mathrm{E}_{\mathrm{ab}}$. Data obtained using white background were used for colour assessments. Colour variation was calculated using the following equation:

$$
\Delta \mathrm{E}_{\mathrm{ab}}^{*}=\left[\left(\Delta \mathrm{L}^{*}\right)^{2}+\left(\Delta \mathrm{a}^{*}\right)^{2}+\left(\Delta \mathrm{b}^{*}\right)^{2}\right]^{1 / 2}
$$

\subsection{Translucency assessment}

Translucency was expressed using the translucency parameter (TP), which was determined by calculating the colour difference between the $L^{*}, a^{*}$ and $b^{*}$ coordinates obtained over black and white backgrounds for each specimen, using the formula:

$$
T P=\left[\left(L_{B}^{*}-L_{w}^{*}\right)^{2}+\left(a_{B}^{*}-a_{w}^{*}\right)^{2}+\left(b_{B}^{*}-b_{w}^{*}\right)^{2}\right]^{1 / 2} \text {. }
$$

The subscript $B$ refers to the colour coordinates of the specimens over the black background and the subscript $\mathrm{W}$ refers to those measurements over the white background.

\subsection{Gloss analysis}

Surface gloss was measured using a glossmeter (NovoCurve, Rhopoint TM, East Sussex, England), with a 2 $\mathrm{mm} \times 2 \mathrm{~mm}$ area and $\mathrm{a} 60^{\circ}$ geometry (light incidence), with values expressed in Gloss Units (GU). The measuring principle of this device is based on a light beam incident to a surface at $60^{\circ}$, and the glossmeter measures the intensity of the reflected light and compares it to a reference value. Three readings were carried out of each specimen and they were averaged to obtain a single value for each specimen during each assessment period.

\subsection{Microhardness analysis}

The surface microhardness (KHN) was assessed using a Knoop Microhardness Tested (FM-700, Future-Tech,

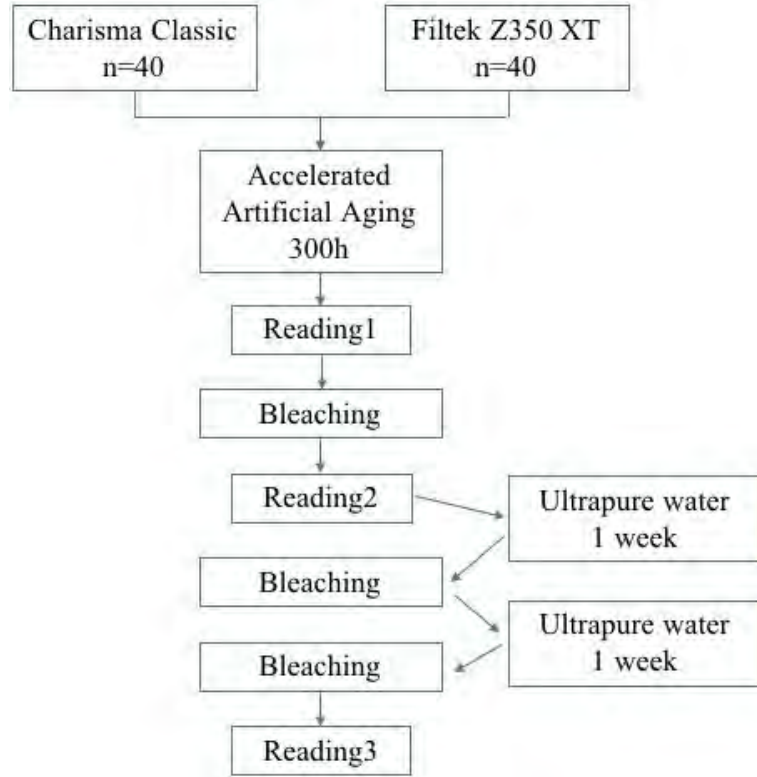

Figure 2. Schematic chart.

Tokyo, Japan), with a $25 \mathrm{~g}$ load for 10 seconds. Three random measurements were carried out on each specimen and the average represented each data point.

\subsection{Bleaching}

Bleaching procedures were performed in three sessions one week apart from each other. In each session, specimens received a layer of 35\% hydrogen peroxide gel (Whiteness HP, FGM Ltda., Joinville, Santa Catarina, Brazil) during four sessions of 15 minutes, totaling 1 hour. In between sessions, the specimens were stored in ultrapure water under constant temperature in a bacteriological oven $\left(37^{\circ} \mathrm{C}+1^{\circ} \mathrm{C}\right)$.

Colour, translucency, gloss and microhardness were analyzed considering the baseline (Reading 1), the first (Reading 2) and last (Reading 3) bleaching sessions, being the last two readings performed right after the bleaching protocol. Figure 2 shows a schematic chart illustrating the experimental design of this study.

\subsection{Statistical Analysis}

Assumptions of the normal distribution (KolmogorovSmirnov test) were checked for all the variables tested. Data were statistically analyzed using STATISTICA software (StatSoft, version 8.0, 2010). Two-Way ANOVA was performed for colour analysis, followed by Tukey's test with $5 \%$ significance. All other parameters were analyzed by Two-way repeated measures ANOVA, followed by Tukey's test with $5 \%$ significance.

\section{Results}

\subsection{Colour change}

The mean and standard deviation values of the colour change $(\Delta \mathrm{E})$ for tested resin composites during bleaching related to the artificial aging are presented in Table 3. In relation to colour changes $(\Delta \mathrm{E})$ after bleaching (Reading 1-Reading 2 and Reading 1-Reading 3), both materials tested did not present significant differences $(p>0.05)$.

\subsection{Translucency}

The two-way repeated measures ANOVA showed significant differences in TP for resin composites $(p<$ 
$0.01)$ and readings $(p<0.01)$, with no interaction of factors $(p=0.901)$. Charisma Classic overall presented lower TP in comparison to Filtek Z350 XT. For both resin composites, increased translucency was observed over time; this increase was detected after the first week after bleaching for Charisma Classic, while Filtek Z350 XT presented increased TP only in the third week of bleaching (Table 4).

\subsection{Gloss}

Gloss values as a function of time (baseline (before bleaching and after aging), 1 and 3 weeks after bleaching) are shown in Table 5. Reduction of gloss values was noticed after 1 week for Charisma Classic with no further reduction over time $(p<0.01)$. For Filtek Z350 XT, surface gloss reduction was detected only after the third week of treatment $(p<0.01)$. In terms of absolute gloss values, resin composite Charisma Classic presented lower gloss values.

\subsection{Microhardness analysis}

The values obtained for KHN are shown in Table 6. Twoway repeated measures ANOVA showed significant differences between the resin composite $(p<0.01)$ while the time (baseline, 1 and 3 week) was not ( $p=$ 0.63 ), nor was the interaction between factors ( $p=$ 0.87). Charisma Classic presented KHN mean values lower than Filtek Z350 XT.

\section{Discussion}

The influence of bleaching and artificial aging procedures on the optical and mechanical properties of resin composite has been investigated $[6,9,16]$. It was expected that the bleaching procedure had no effects on the properties studied. However, this was not observed and, consequently, the null hypothesis was rejected. The results revealed that 35\% hydrogen peroxide bleaching procedure was able to increase the translucency and reduce the gloss of aged resin composites. No differences were detected regarding colour and microhardness variations.

The optical and mechanical properties of resin composites can be influenced by several factors, including the aging process, bleaching procedures, as well by characteristics related to restorative material $[5,7,23-25]$. The UV-accelerated aging has a photooxidative potential, by means of the action of both UV radiation and water, inducing the cleavage of simple and double carbon bounds found in the resin matrix, such as Bis-GMA, UDMA and TEGDMA, being responsible for the material deterioration and changes in properties $[9,23,26,27]$. Regarding bleaching procedures, oxidative cleavage of polymer-chains by means of free prehydroxyl $\left(\mathrm{HO}^{2-}\right)$ radicals, resulting from the degradation of the $\mathrm{H}_{2} \mathrm{O}_{2^{\prime}}$ have been suggested to explain the colour changes of restorative materials [28]. Water and molecular oxygen are also released during the reaction [29]. Such release may accelerate the hydrolytic degradation, and lead to colour changes of resin composites. In addition, factors related to composites can influence colour, including wear, matrix structure, volume and type of filler, and weakening of matrix-filler bonding $[22,25,30]$. Thus, a composite with higher resin matrix content is expected to be more prone to degradation and colour changes after bleaching treatment [31]. Although they presented
Table 3. Mean values $( \pm \mathrm{SD})$ of colour change $(\Delta \mathrm{E})$ and results of Tukey's test.

\begin{tabular}{lll}
\hline & Charisma Classic & Filtek Z350 XT \\
\hline Reading1-Reading 2 & $2.21( \pm 0.95) \mathrm{Aa}$ & $1.92( \pm 0.44) \mathrm{Aa}$ \\
Reading1-Reading 3 & $2.08( \pm 1.14) \mathrm{Aa}$ & $2.44( \pm 0.66) \mathrm{Aa}$ \\
\hline
\end{tabular}

In each row, distinct capital letters indicate significant difference between resin composite while distinct lowercase letters in each column, indicate significant difference among weeks $(a=0.05)$.

Table 4. Mean values ( \pm SD) of translucency parameter (TP) and results ofTukey's test.

\begin{tabular}{lll}
\hline & Charisma Classic & Filtek Z350 XT \\
\hline Reading 1 & $23.02( \pm 5.62) \mathrm{Aa}$ & $26.4( \pm 5.11) \mathrm{Ba}$ \\
Reading 2 & $33.16( \pm 1.95) \mathrm{Ab}$ & $37.31( \pm 3.88) \mathrm{Bb}$ \\
Reading 3 & $30.9( \pm 2.39) \mathrm{Ab}$ & $35.42( \pm 4.18) \mathrm{Bb}$ \\
\hline
\end{tabular}

In each row, distinct capital letters indicate significant difference between resin composite while distinct lowercase letters in each column, indicate significant difference among weeks $(a=0.05)$.

Table 5. Mean values ( \pm SD) of gloss and results of Tukey's test.

\begin{tabular}{lll}
\hline & Charisma Classic & Filtek Z350 XT \\
\hline Reading 1 & $79.53( \pm 8.54) \mathrm{Aa}$ & $84.77( \pm 4.03) \mathrm{Aa}$ \\
Reading 2 & $66.57( \pm 12.15) \mathrm{Ab}$ & $84.37( \pm 4.52) \mathrm{Ba}$ \\
Reading 3 & $63.42( \pm 9.1) \mathrm{Ab}$ & $67.5( \pm 5.24) \mathrm{Ab}$ \\
\hline
\end{tabular}

In each row, distinct capital letters indicate significant difference between resin composite while distinct lowercase letters in each column, indicate significant difference among weeks $(a=0.05)$.

different fillers, both resin composites present Bis-GMA in its composition, and it might have influenced the presently assessed colour stability for both nanohybrid and microhybrid aged resin composites. Previous studies on the effect of bleaching on the properties of aged composites reported conflicting results. The discrepancies between those studies may be caused by the type of aging protocol, bleaching agents used and total application time of agents or the type of resin composite tested. Some studies have shown a significant colour change for resin composite Charisma [16] or Filtek Supreme [9], while others did not [16]. Comparing the present data on aged resin composites to other studies in which aging was not performed $[5,7]$, the bleaching process resulted in similar patterns of colour alterations, suggesting bleaching may behave similarly to aged and non-aged resin composite.

As reported by other studies $[3,6]$, the potential effect of bleaching treatment depends on the type, concentration of bleaching agent, and the resin composite brand. For instance, it has been reported that Filtek resin composite presented different behavior to colour change after bleaching when compared to another nanohybrid resin composite [3]. Moreover, $16 \%$ carbamide peroxide is reported to be more effective for bleaching therapy than 35\% hydrogen peroxide, and stained resin composites for enamel are more prone to bleaching. Besides that, the exposure time of resin composites to bleaching agent plays an even more important role to the material properties, since an extended exposure is more deleterious than higher concentration [6]. This can be attributed to the colour results of the present study. Translucency is related to light transmission, absorption, scattering and reflection [22]. This property is influenced by the difference between the refractive index of the resin matrix and filler particles, filler size, distribution, 
concentration, pigments and defects like voids [30,32]. The increase of particles weight percent in resin composite (ranging from 10 to $70 \%$ ) reduced the translucency of the material. Additionally, the increase in particle size is also reported to result in increased translucency when comparing $0.77 \mu \mathrm{m}$ with $0.50 \mathrm{~m}$ fillers [32]. In the present study, an increased TP for Filtek Z350 XT was observed. It was reported that aging can change the translucency of the composites due to changes in scattering and absorption properties [33].

Previous studies reported that water from the bleaching agent is released during the bleaching procedures $[29,34]$ and it is able to penetrate within the polymer chains and stay between the layers $[27,35]$. This process can induce hydrolytic degradation of the material $[29,34,36]$, leading to filler-matrix interface debonding and changes in optical properties due to an altered pattern of light diffusion [32,33,36]. One might question this statement regarding the presence of water in the oral environment during the whole restoration service. The authors believe that the bleaching therapy exacerbates the potential of water influence on resin composites. In addition, the hydrophilic characteristics of the monomers present in resin composites may have contributed to translucency changes [36]. The presence of Bis-GMA and TEGDMA monomers, which present great susceptibility to hydrolysis, may lead to a water uptake and monomer elution and consequently an alteration in the light refraction index of the polymer matrix [37]. Those considerations might contribute to explain the translucency behavior detected. However, this condition needs to be further investigated.

One of the reasons for studying the surface gloss of materials relies on the fact they might influence colour matching/selection in clinical conditions [38]. It has been reported that the gloss is altered after bleaching procedures $[7,9]$. Once the material already presents a state of degradation, bleaching may worsen this condition. In theory, the deterioration or wear of materials can produce changes in surface gloss, resulting in esthetic changes [23,39]. Light reflection is related to filler size [40]. Small filler sizes are reported to present greater surface gloss than large fillers under the same polishing procedures, leading to greater specular reflection [41]. In the present study, the bleaching decreased gloss for all tested materials, and no differences were detected between nanohybrid and microhybrid aged composites. Possibly, the superficial layer was degraded due to the erosion of the resin matrix [7], a fact that might be the reason for the present results. Thus, the fillers were exposed, altering the surface topography, and therefore less gloss was detected.

Comparing the present data on aged resin composites to non-aged resin composite studies [7,8], the bleaching process resulted in similar patterns of surface gloss decrease, suggesting bleaching may behave similarly to aged and non-aged resin composite regarding such property.

It was observed that the application of the bleaching agent was not able to change the microhardness of the tested composites, confirming our expectations. The effect of the bleaching agent on microhardness seems to be related to the oxidation process, as previously described [14]. The oxidative cleavage of polymer chains induced by the free radicals released by hydrogen peroxide leads to chemical softening of the dental materials [14]. In this study, different results would possibly be detected with increased bleaching time. It is important to emphasize that the microhardness of the two tested resin composites was different. The higher microhardness values of the Filtek Z350 XT are expected due to the presence of nanoclusters combined with nanoparticles, which reduce the interstitial space, improving the physical properties [42]. From these results, it was found that microhardness results were only material dependent.

Notwithstanding the low amount of studies and methodological variability, it has to be highlighted that aging and bleaching procedures produce relevant changes in the properties of the resin composite, which are material dependent. Although these changes might not be clinically observed, bleaching agents can lead to microcracks in the resin composite's surface. This might influence the clinical acceptability of resin composite restorations concerning the longevity, and further necessity of repair or replacement. Therefore, this study provides interesting information and support further investigations to complement the present obtained results.

\section{Conclusion}

Considering the limitations, the results of this in vitro study provide useful additional information on the optical and mechanical properties of aged resins after bleaching procedures. It is concluded that colour and microhardness were constant, before and after bleaching procedures. The bleaching agents were able to increase translucency and reduce the gloss of aged resin composites. Microhybrid composite showed lower values for all the parameters assessed when compared to the nanohybrid composite.

\section{Author Contributions}

IFM: Study design, laboratory testing, discussion of results, manuscript writing, and final manuscript approval; AMC: Study design, laboratory testing, discussion of results and manuscript writing, and final manuscript approval; DCD: Study design, laboratory testing, discussion of results, and final manuscript approval; MCV: Study design, and discussion of results, and final manuscript approval; RMM: Study design, and discussion of results, and final manuscript approval; EB: Study design, statistical analysis, interpretations of data, and manuscript writing, and final manuscript approval.

\section{Disclosure}

The authors do not have any financial interest in the companies whose materials are included in this article.

\section{Acknowledgements}

This study has been partially financed by the Coordenação de Aperfeiçoamento de Pessoal de Nível Superior - Brasil (CAPES) - Finance code 001.

\section{References}

1. Basting R, Amaral F, França F, Flório F. Clinical comparative study of the effectiveness of and tooth sensitivity to $10 \%$ and $20 \%$ carbamide peroxide home-use and $35 \%$ and $38 \%$ hydrogen 
peroxide in-office bleaching materials containing desensitizing agents. Oper Dent. 2012;37(5):467-473. doi:10.2341/11-337-C.

[Full text links] [PubMed] Google Scholar(126) Scopus(63)

2. Lima DANL, Aguiar FHB, Liporoni PCS, et al. Influence of chemical or physical catalysts on high concentration bleaching agents. Eur J Esthet Dent. 2011;6(4):454-466

[Full text links] [PubMed] Google Scholar(15) Scopus(6)

3. Farah RI, Elwi H. Spectrophotometric evaluation of color changes of bleach-shade resin-based composites after staining and bleaching. J Contemp Dent Pract. 2014;15(5):587-594. [Full text links] [PubMed] Google Scholar(11) Scopus(5)

4. Xing W, Jiang T, Liang S, et al. Effect of in-office bleaching agents on the colour changes of stained ceromers and direct composite resins. Acta Odontol Scand. 2014;72(8):1032-1038. doi: 10.3109/00016357.2014.946962.

[Full text links] [PubMed] Google Scholar(2) Scopus(1)

5. Torres CRG, Ribeiro CF, Bresciani E, Borges AB. Influence of hydrogen peroxide bleaching gels on color, opacity, and fluorescence of composite resins. Oper Dent. 2012;37(5):526-531. doi:10.2341/11-189-L.

[Full text links] [PubMed] Google Scholar(14) Scopus(6)

6. Lago M, Mozzaquatro LR, Rodrigues C, et al. Influence of bleaching agents on colour and translucency of aged resin composites. J Esthet Restor Dent. 2017;29(5):368-377. doi:10.1111/jerd.12261.

[Full text links] [PubMed] Google Scholar(3) Scopus(1)

7. Anagnostou M, Chelioti G, Chioti S, Kakaboura A. Effect of toothbleaching methods on gloss and color of resin composites. J Dent 2010;38(Suppl 2):e129-e136. doi:10.1016/j.dent.2010.06.006. [Full text links] [PubMed] Google Scholar(34) Scopus(14)

8. Yalcin F, Gürgan S. Effect of two different bleaching regimens on the gloss of tooth colored restorative materials. Dent Mater. 2005;21(5):464-468.

[Full text links] [PubMed] Google Scholar(63) Scopus(24)

9. Gouveia THN, Públio JC, Ambrosano GMB, et al. Effect of at-home bleaching with different thickeners and aging on physical properties of a nanocomposite. Eur J Dent. 2016;10(1):82-91. doi:10.4103/1305-7456.175683.

[Full text links] [Free PMC Article] [PubMed] Google Scholar(11) Scopus(4)

10. AlQahtani M. The effect of a $10 \%$ carbamide peroxide bleaching agent on the microhardness of four types of direct resinbased restorative materials. Oper Dent. 2013;38(3):316-323. doi:10.2341/12-224-L

[Full text links] [PubMed] Google Scholar(32) Scopus(10)

11. Sharafeddin F, Jamalipour G. Effects of $35 \%$ carbamide peroxide gel on surface roughness and hardness of composite resins. J Dent (Tehran). 2010;7(1):6-12.

[Full text links] [Free PMC Article] [PubMed] Google Scholar(40)

12. Kamangar SSH, Kiakojoori K, Mirzaii M, Fard MJK. Effects of $15 \%$ carbamide peroxide and $40 \%$ hydrogen peroxide on the microhardness and color change of composite resins. J Dent (Tehran), 2014:11(2):196-209.

[Full text links] [Free PMC Article] [PubMed] Google Scholar(17)

13. Malkondu O, Yurdagüven H, Say EC, Kazazoglu E, Soyman M. Effect of bleaching on microhardness of esthetic restorative materials. Oper Dent. 2011:36(2):177-186. doi:10.2341/10-078-L [Full text links] [PubMed] Google Scholar(56) Scopus(26)

14. Hannig C, Duong S, Becker K, et al. Effect of bleaching on subsurface micro-hardness of composite and a polyacid modified composite. Dent Mater. 2007;23(2):198-203.

[Full text links] [PubMed] Google Scholar(116) Scopus(49)

15. Weir MD, Moreau JL, Levine ED, et al. Nanocomposite containing CaF2 nanoparticles: Thermal cycling, wear and long-term water-aging. Dent Mater. 2012;28(6):642-652. doi:10.1016/j. dental.2012.02.007.

[Full text links] [Free PMC Article] [PubMed] Google Scholar(43)

16. Rattacaso RMB, Garcia LFR, Aguilar FG, Consani S, Pires-de-Souza FCP. Bleaching agent action on color stability, surface roughness and microhardness of composites submitted to accelerated artificial aging. Eur J Dent. 2011;5(2):143-149.

[Free PMC Article] [PubMed] Google Scholar(12) Scopus(14)

17. Mendes APKF, Barceleiro MO, Reis RSA, Bonato LL, Dias KRHC. Changes in surface roughness and color stability of two composites caused by different bleaching agents. Braz Dent J. 2012;23(6):659-666. doi:10.1590/S0103-6442012000600006. [Full text links] [PubMed] Google Scholar(27) Scopus(12)

18. Xu HHK. Long-term water-aging of whisker-reinforced polymer-matrix composites. J Dent Res. 2003;82(1):48-52. doi:10.1177/154405910308200111.

[Full text links] [PubMed] Google Scholar(32) Scopus(21)

19. Ferracane $\mathrm{JL}$, Berge HX, Condon JR. In vitro aging of dental composites in water - Effect of degree of conversion, filler volume, and filler/matrix coupling. J Biomed Mater Res. 1998:42(3):465-472 [Full text links] [PubMed] Google Scholar(597) Scopus(379)

20. Heydecke G, Zhang F, Razzoog ME. In vitro color stability of double-layer veneers after accelerated aging. J Prosthet Dent. 2001;85(6):551-557.

[Full text links] [PubMed] Google Scholar(86) Scopus(44)
21. Göhring TN, Zehnder M, Sener B, Schmidlin PR. In vitro microleakage of adhesive-sealed dentin with lactic acid and saliva exposure: a radio-isotope analysis. J Dent. 2004;32(3):235-240. [Full text links] [PubMed] Google Scholar(47) Scopus(34)

22. Caneppele TM, Borges AB, Torres CR. Effects of dental bleaching on the color, translucency and fluorescence properties of enamel and dentin. Eur J Esthet Dent. 2013;8(2):200-212.

[Full text links] [PubMed] Google Scholar(18) Scopus(9)

23. Salgado VE, Cavalcante LM, Moraes RR, et al. Degradation of optical and surface properties of resin-based composites with distinct nanoparticle sizes but equivalent surface area. J Dent 2017;59:48-53. doi:10.1016/j.dent.2017.02.008. [Full text links] [PubMed] Google Scholar(4) Scopus(2)

24. Rocha RS, Oliveira AC, Caneppele TMF, Bresciani E. Effect of artificial aging protocols on surface gloss of resin composites. Int J Dent. 2017;2017. doi:10.1155/2017/3483171.

[Full text links] [Free PMC Article] [PubMed] Google Scholar(2) Scopus(1)

25. Kurtulmus-Yilmaz S, Cengiz E, Ulusoy N, Ozak ST, Yuksel E. The effect of home-bleaching application on the color and translucency of five resin composites. J Dent. 2013;41(Suppl 5):e70-e75. doi:10.1016/j.dent.2012.12.007.

[Full text links] [PubMed] Google Scholar(20) Scopus(11)

26. Takahashi MK, Vieira S, Rached RN, et al. Fluorescence intensity of resin composites and dental tissues before and after accelerated aging: a comparative study. Oper Dent. 2008:33(2):189-195. doi:10.2341/07-74. [Full text links] [PubMed] Google Scholar(53) Scopus(21)

27. Sideridou ID, Karabela MM, Bikiaris DN. Aging studies of light cured dimethacrylate-based dental resins and a resin composite in water or ethanol/water. Dent Mater. 2007;23(9):1142-1149. [Full text links] [PubMed] Google Scholar(69) Scopus(34)

28. Fasanaro TS. Bleaching teeth: history, chemicals, and methods used for common tooth discolorations. J Esthet Dent. 1992;4(3):71-78. [Full text links] [PubMed] Google Scholar(177) Scopus(54)

29. Söderholm KJ, Zigan M, Ragan M, Fischlschweiger W, Bergman M. Hydrolytic degradation of dental composites. J Dent Res. 1984;63(10):1248-1254.

[Full text links] [PubMed] Google Scholar(559) Scopus(344)

30. Yu B, Ahn JS, Lim Jl, Lee YK. Influence of TiO2 nanoparticles on the optical properties of resin composites. Dent Mater. 2009;25(9):1142-1147. doi:10.1016/j.dental.2009.03.012. [Full text links] [PubMed] Google Scholar(54) Scopus(37)

31. Kim JH, Lee YK, Lim BS, Rhee SH, Yang HC. Effect of tooth-whitening strips and films on changes in color and surface roughness of resin composites. Clin Oral Investig. 2004;8(3):118-122.

[Full text links] [PubMed] Google Scholar(69) Scopus(19)

32. Lee YK. Influence of filler on the difference between the transmitted and reflected colors of experimental resin composites. Dent Mater. 2008;24(9):1243-1247. doi:10.1016/j. dental.2008.01.014

[Full text links] [PubMed] Google Scholar(113) Scopus(63)

33. Lee YK, Lim BS, Rhee SH, Yang HC, Lim YK. Changes in scattering and absorption properties of esthetic filling materials after aging J Biomed Mater Res B Appl Biomater. 2007:80(1):131-139. [Full text links] [PubMed] Google Scholar(16) Scopus(5)

34. Ferracane JL. Hygroscopic and hydrolytic effects in dental polymer networks. Dent Mater. 2006;22(3):211-222.

[Full text links] [PubMed] Google Scholar(934) Scopus(539)

35. Kalachandra S. Influence of fillers on the water sorption of composites. Dent Mater. 1989;5(4):283-288. [Full text links] [PubMed] Google Scholar(117) Scopus(72)

36. Vichi A, Ferrari $M$, Davidson CL. Color and opacity variations in three different resin-based composite products after water aging. Dent Mater. 2004;20(6):530-534.

[Full text links] [PubMed] Google Scholar(315) Scopus(147)

37. Rocha ACC, Lima CSA, Santos MCMS, Montes MAJR. Evaluation of surface roughness of a nanofill resin composite after simulated brushing and immersion in mouthrinses, alcohol and water. Mater Res. 2010;13(1):77-80. doi:10.1590/S1516-14392010000100016. [Full text links] Google Scholar(24)

38. O'Brien WJ, Johnston WM, Fanian F, Lambert S. The surface roughness and gloss of composites. J Dent Res. 1984;63(5):685-688. [Full text links] [PubMed] Google Scholar(89) Scopus(55)

39. Salgado VE, Cavalcante LM, Silikas N, Schneider LFJ. The influence of nanoscale inorganic content over optical and surface properties of model composites. J Dent. 2013;41(Suppl 5):e45-e53 doi:10.1016/j.dent 2013.05.011.

[Full text links] [PubMed] Google Scholar(22) Scopus(16)

40. Lee YKK, Lim BSS, Rhee SHH, Yang HCC, Powers JM. Color and translucency of $A 2$ shade resin composites after curing, polishing and thermocycling. Oper Dent. 2005:30(4):436-442.

[Full text links] [PubMed] Google Scholar(88) Scopus(46)

41. Furuse AY, Gordon K, Rodrigues FP, Silikas N, Watts DC. Colourstability and gloss retention of silorane and dimethacrylate composites with accelerated aging. J Dent. 2008; 36(11):945-952 doi: 10.1016/j.jdent 2008.08.001.

[Full text links] [PubMed] GoogleScholar(111) Scopus(44)

42. Yap AU, Yap SH, Teo CK, Ng JJ. Comparison of surface finish of new aesthetic restorative materials. Oper Dent. 2004;29(1):100-104. [Full text links] [PubMed] Google Scholar(112) Scopus(47) 


\section{Ingrid Fernandes MATHIAS-SANTAMARIA}

DDS, MS, PhD Student

Department of Restorative Dentistry

Institute of Science and Technology, São Paulo State University São José dos Campos, Brazil

Ingrid Fernandes Mathias-Santamaria, DDS, MS, PhD Student, got her degrees at the Institute of Science and Technology of São José dos Campos, São Paulo State University - UNESP, Brazil. She has experience with laboratory and clinical research applying dental materials, studying the behavior of direct resin composites.

\section{Ouestions}

\section{Which method was used to assess colour and gloss?}

口a. Spectrophotometer and Glossmeter, respectively;

b. Glossmeter and Spectrophotometer, respectively;

ac. Spectrophotometer only;

ad. None of above.

\section{Which was the result of the study?}

a. All the parameters were influenced by the bleaching therapy;

b. None of the parameters were influenced by the bleaching therapy;

ac. Gloss decreased, and colour and microhardness were not influenced by the bleaching therapy;

$\square d$. None of the optical parameters changed after bleaching therapy.

\section{Which was the bleaching therapy used?}

a. 35\% hydrogen peroxide for 20 minutes per application, three sessions;

b. $35 \%$ carbamide peroxide for 15 minutes per application, three sessions;

b. 35\% carbamide peroxide for 15 minutes per session, three sessions:

$\square$ d. $35 \%$ hydrogen peroxide for 60 minutes per session, three sessions.

\section{Regarding the artificial accelerated aging used, choose the correct alternative:}

$\square$ a. Resin composites were not aged in this study;

b. Aging was performed for $300 \mathrm{~h}$ using a UV-light chamber, simulating one year of clinical service;

口c. Aging was performed for $300 \mathrm{~h}$ using a UV-light chamber, simulating one year and a half of clinical service;

口d. Aging was performed for 300 aging cycles using a UV-light chamber, simulating one year of clinical service.

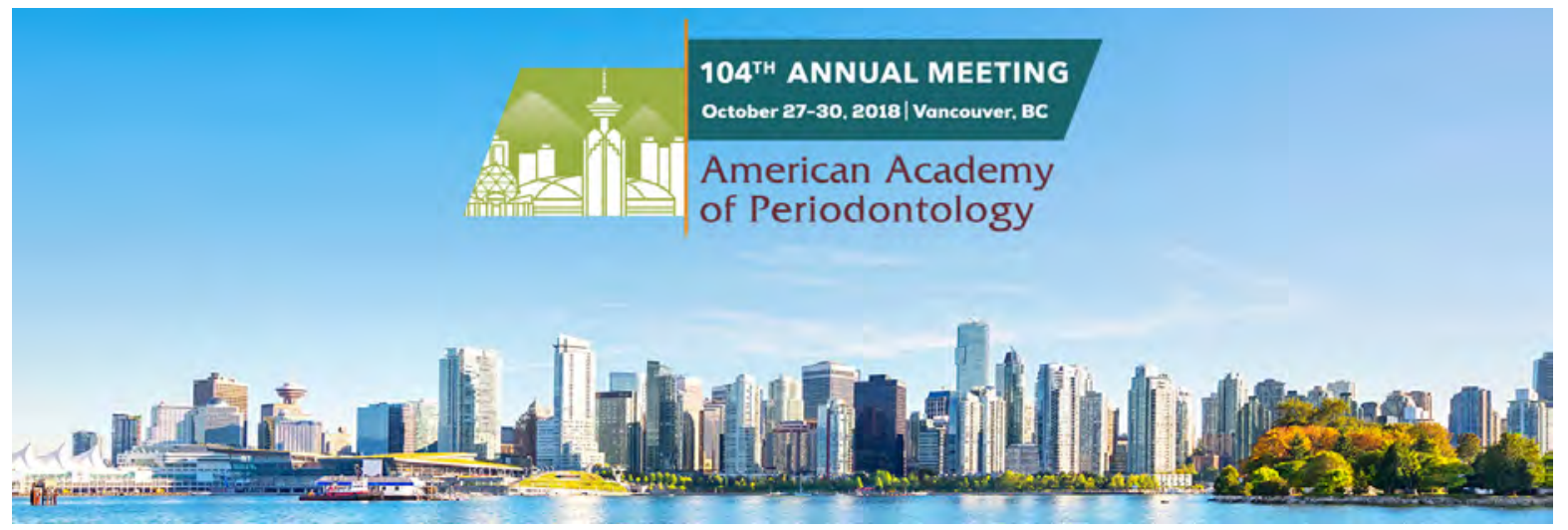

https://members.perio.org/am2018/home?ssopc=1 